\title{
Self-transcendence and Eros: The human condition between desire and the infinite
}

Author:
Cornel W. du Toit ${ }^{1}$
Affiliation:
'Research Institute for
Theology and Religion,
University of South Africa,
South Africa
Correspondence to:
Cornel du Toit
Email:
dtoitcw@unisa.ac.za
Postal address:
PO Box 392, Unisa 003 ,
South Africa
Dates:
Received: 17 Aug. 2010
Accepted: 30 Oct. 2010
Published: 12 July 2011
How to cite this article:
Du Toit, C.W., 2011, 'Self-
transcendence and Eros:
The human condition
between desire and the
infinite', HTS Teologiese
Studies/Theological Studies
67(3), Art. \#944, 12 pages.
doi:10.4102/hts.v67i3.944

(C) 2011. The Authors. Licensee: AOSIS OpenJournals. This work is licensed under the Creative Commons Attribution License.
This article treats self-transcendence - like all transcendence - as a fact of human life. Inter alia this means that the human mind perforce operates in terms of binary concepts such as finitude-infinity, inner world-outside world, self-other, desire-fulfilment, separation-union and the like. We find these concepts in most myths of origin. The concept of desire (Eros), combining unfulfilment and the infinite, particularly epitomises self-transcendence. Ralph Waldo Emerson is cited as a precursor of the mid-19th century transcendentalists, whose ideas are resurfacing in present-day secular spirituality. In this article, we examined desire in the Christian conception of the Fall as envisioned by the Jewish philosopher Martin Buber and by Hegel, who integrates mind and nature in his philosophy of Spirit. The works of Emmanuel Levinas and Paul Ricoeur are used as points of reference to help us understand self and other in a framework of self-transcendence. The impact of these ideas on a postmetaphysical epistemology was also explored. Affectivity is a neglected area in Western thought and displays the same infinitude as rationality. The article concluded with present-day strategies of self-construction in a techno-scientific consumer culture.

\section{Introduction}

\section{Transcendence and post-transcendence}

Ours is a post-transcendent era. Human dogma has unravelled God, metaphysics has unravelled existence and science has unravelled the cosmos. People have become transparent to each other and no longer relate. The world around us has become explicable and we are left disillusioned in a disenchanted environment. The postmodern mind mourns the loss of mystery, the challenge of the unknown, the desirable and enticing, and the loss of an enchanted world. When we speak of the death of God, the end of metaphysics, the end of subjectivity and the technological transformation of nature, we are actually speaking of a loss of transcendent experience. We do not merely mourn the loss but are continually looking for new experiences of transcendence. Yet does a statement like 'the death of God' not rule out any experience of radical transcendence? ${ }^{1}$

We need to redefine transcendence for those who no longer believe that our world is governed by such unknown forces. Metaphysical constructs that were once used to describe supernatural forces (good or evil) have lost their plausibility. Our world is subject to laws of nature and these laws, rather than miracles or supernatural forces, rule our destiny. The role of transcendent forces in people's personal lives, too, is questioned. We should not look for divine or impersonal agents to explain misfortunes that befall us. Evil, suffering and injustice are part of life, of our particular society, or simply coincidence. Does that mean that human life has become onedimensionally immanent, or is it merely a new phase in our mental evolution? The transcendent (unknown forces and influences) has not vanished from human life, but is at most regarded as an immanent factor residing mainly in the self. Transcendence, in the sense of unpredictable, unfathomable but also exciting and innovative forces, is to be found in the unconscious, the imagination, dreams, conscience, desire and fantasy. These are things that constitute our daily lives, a protean driving force. They can be called infinite, for they appear to be inexhaustible and manifest differently in every phase of life. To many, the cardinal form of transcendence remains the God of their religion, to whom they relate. To others it is the interior space of the self, whose unfathomable depths they must plumb. This is done via a mystical 'journey' into the self, culminating in a transcendent experience, in which the self encounters God or astonishing ideas. ${ }^{2}$ The contemporary reinterpretation of transcendence and self-transcendence evident in secular spirituality and aspects of the New Age movement has its antecedents in the transcendentalist

1.Vattimo (2003:32) writes: 'Nietzsche had already perceived that belief in God cannot be replaced by belief in an objective truth capable of disproving religion and setting us free from the errors and lies of the priests. This truth more true than the God of the priests would then be the true God, even more dangerous and unacceptable than the one of ecclesiastical tradition.'

2.Possible criticism of mystical experiences or the 'inward journey' is that it eliminates others (and even the self in some of its forms). Is religion possible without the O/other? Certainly ethics is not. Mystical practices are easily reduced to mere techniques to activate certain brain functions (AUB phenomena - Absolute Unitary Being - experienced as euphoric union with the All or the deity through deafferentation (elimination of sensory input) and other meditative techniques. 
and Romantic movements in mid-19th century America, in which Ralph Waldo Emerson was a leading figure.

My thesis, in a nutshell, is as follows. Transcendence is innately human and manifests itself in desire, which is open and infinite. Christianity attributes transcendence exclusively to the 'totally other' dimension of God. It disregards the fact that the human mind is wired for transcendence. Humans including their openness to the future (desire) - are reduced to sinfulness. The sole, remotely positive characterisation of humans is that they are created in God's image - and that quality they have lost. In the Old Testament they await the Messiah to bring deliverance; in the New Testament they gain it purely in their attributed (Pauline) status of being 'in Christ'. The closest it gets to acknowledging openness and desire, which is what I propose doing here, is the dictum: 'Become what you are.' But even this dictum is hamstrung by the Christian ethos of that age. In our present context of immanent transcendence this fixated anthropology is incongruous. My basic premise, to be developed below, is that we are wired for desire in its open, infinite, futureoriented dimension. Transcendence is integrally human; hence religion, imagination, inventiveness, fantasy and constant flux are permanent features of our history. Immanent transcendence is an anthropological datum. It is not confined to Europe and Western culture. Desire in the sense proposed here is common to all cultures: African, Eastern and Western alike.

I begin my argument by outlining the transcendental tradition that started with Emerson. I then examine human incompleteness between desire and the infinite with reference to the Greek legacy, before looking at Christianity's relative disregard for desire and infinitude as essential to the human self, with specific reference to the biblical myth of the Fall and some responses to it. The next sections describe the infinitude of the self in relation to that of others and the role of affect as an essential corrective to religious and scientific rationalism, which allows little room for openness. Finally, I offer a critique of the infinite dimension of the self in a consumer culture.

\section{Emerson: Transcendence via the unconscious, affect, Eros and nature}

Emerson's thinking is an essential background to understand the pertinence of immanent transcendence in our day and age. He was a forerunner of the accent on transcendence as part and parcel of the human self. He not only acted as a counterweight to the rationalism of his time, but paved the way for present-day secular spirituality. Emerson described his time (the mid-19th century) as bogged down in conventional traditions, dogmas and practices, partly as a result of the tyranny of rationalism (experienced at Harvard Divinity School where he studied and in the Unitarian Church where he ministered). The affective side of human nature was suppressed, so the people of his day were cut off from their emotional roots:
The primary deficiency of the age was ... its inability to connect with the primal, erotic, instinctive, and intuitional element within, the affective side of humanity that connects us with divinity itself and also binds us to one another.

(Gougeon 2007:4)

Emerson's transcendental philosophy ${ }^{3}$ propounded the dignity, rights and divinity of all human beings. It contributed greatly to the emancipation of slaves and the establishment of women's rights. Today, human rights are the very core of social ethics. Emerson's transcendental vision was one of personal harmony and primordial union with nature, God, the unconscious, affect and intuition. Alienation is the result of losing contact with our matrix. In the beginning the gods divided a solitary Human (Man) into many people, just as the hand ramifies into fingers in order to be more efficient. That lost unity can be regained. 'For Emerson the source of this original unity is still with us. It is the power of Eros, the OverSoul, the "divine Reason"' (Gougeon 2007:6). Our overrated rationality needs to be complemented with all other aspects of existence to restore wholeness:

The balanced unity of mind and body, conscious and unconscious, self and nature, is an essential element in reaching transcendence which, for them, was the firsthand experience of divinity.

(Gougeon 2007:49)

To Emerson's mind we can overcome our dissatisfaction with overrated rationality ${ }^{4}$ by means of a transcendental descent into the depths of our nature, which brings fulfilment not attainable in a one-dimensionally rational ${ }^{5}$ existence. In contrast to the Christianity of his day, which he considered oppressive, he did not seek fulfilment in a spiritualised reality. Instead of a transcendental encounter via Holy Scriptures or proclamation, or via a spiritualised 'beyond' or 'above', he proposed a movement, via human corporeality, first inwards, then outwards (see Gill 1989). Human nature, or more specifically the unconscious, affect, intuition, eroticism, the imagination and experience, is the primary route to meaning, a sense of unity, authenticity and one's 'true' self. Emerson contributed greatly to belief in the self and its powers, so typical of the New World and the great American Dream. Faith in yourself leads to discovery of the infinite, nature, Eros, the Over-Soul, the imagination, God within you. Only faith in yourself makes the difference that enables you to change the world around you. Hence the transcendent movement was prerequisite for changing the society of Emerson's day: 'sympathy, emotion, imagination, dream, and other life-sustaining functions of the unconscious,

3.Prominent transcendentalists included Henry David Thoreau, Amos Bronson Alcott, Orestes Brownson, William Henry Channing, James Freeman Clarke, John Sullivan Dwight, Margaret Fuller, William Henry Furness, Frederick Henry Hedge, Theodore Parker and George Ripley. Emerson drew on the mysticism of Emanuel Swedenborg and on the German idealists.

4.Reason and consciousness are seen as linked. 'When consciousness dominates, one is faced with a society that has lost its capacity to feel and dream due to its repression of emotion and imagination and its desire to preserve an increasingly opressive (Gougeon 2007:71-72).

5.Consciousness is regarded as the rational, masculine component, whereas nature and the unconscious, where nature manifests itself, represent the feminine, the source of affect and creativity. Emerson accentuates both aspects and, like Jung, source of affect and creativity. Emerson accentuates both aspects and, like Jung,
discerns masculine and feminine aspects of the psyche (also see Gougeon 2007:72, discerns masc 
could provide the libido ballast to revitalize and redeem his society ...' (Gougeon 2007:109).

Emerson laid the foundation for a mentality that, with growing affluence and technological advances, culminated in the present (mainly Western) self-image, which has made self-construction through technological artefacts a practical reality. Today there is renewed interest in a sense of holistic union with nature, a transcendental inward journey (meditative practices), a reappraisal of the corporeal and affective dimensions of life, an accent on imagination and inner creativity, and the like.

\section{Human incompleteness between desire and the infinite}

Transcendence is a mental movement, a thought process: it entails moving from familiar sameness to the new and the unknown; it represents mystery in the mode of strangeness and infinity. Human beings exist in this transcendent mode. Self-transcendence is a tautology because the self exists only in transcendent mode. ${ }^{6}$ Humans experience themselves as individuals, persons, subjects and see themselves as distinct from other people and things. That accounts for binary contrasts such as inner world and outside world, subject and object, self and other, consciousness and self-consciousness. The distinctions are not absolute, because the 'autonomous self' is in fact shaped by people and things outside itself. ${ }^{7}$ Hence self-transcendence does not happen exclusively within the person, between the constructs of ' $\mathrm{I}$ ' and ' $\mathrm{me}^{\prime} .8$ The way we engage continually in new interactions and see things differently changes our identity. As my insight into people and things changes - a constant 'self-correction' - I also change, for I am my insights and beliefs. Without the other self and self-transcendence make no sense. ${ }^{9}$ Emmanuel Levinas realised this and worked it out in his philosophy of 'the face of the other', to which we return below.

It would be reductive to regard descriptions and experiences of transcendence in a particular theological or religious phase of human culture as paradigmatic for our day and age. Transcendence manifests itself spontaneously in a form permitted by a particular culture and worldview. The specific manifestations of transcendence and self-transcendence vary from age to age, but their underlying biological constant is desire.

6.In this context Nancy (2002:40) interprets Hegel as follows: 'Thought must take the self out of itself; it must extract it from its simple being-in-itself: thought is itself such an extraction, along with the speech in which thinking takes itself out of itself and exposes itself'; and 'Sense is therefore what makes itself sensed and what gives itself form in passage and as passage ... it is incessant movement and activity' gives itself form in
(Nancy 2002:50).

7.That determines every self-distinction, as Hegel affirms: 'If $A=A$, it is because $A$ posits itself as other than itself. Logos is subject, which means the exposing of the infinite exposing of identity' (Nancy 2002:21). With reference to the I, he writes: 'The simple position of the $I$ is an abstraction. On the contrary, the concrete awakening of the I is its awakening to the world and by the world - the world of alterity in general' (Nancy 2002:60).

8. Interdependence with others is apparent in the distinction between I and me. 'I' is what I am in my own experience, 'me' is the way others identify me as myself (see Hankiss 2006:331. For more complex examples, see Ryle 1949:180-182).

9. Hegel (see 1959:107, 112) puts it thus: 'Every one is also the other of another and vice versa. If this mutual alienation is comprehended, Being negates its negation and thereby affirms itself as the one in the other. It then remains itself in all changes and transitions. This is true infinity of Being.
Aristophanes's myth about the origin of human nature in Plato's dialogue Symposium (189c-190c) associates the experience of human incompleteness with our origin. In broad outline the picture is as follows. ${ }^{10}$ Originally we were very different from what we are today. We were 'dual' beings with two heads, four arms, four legs and round bodies that enabled us to roll on the ground at great speed. There were three 'genders': a dual female, a dual male, and a man-woman combination. This original state was superior to our present one - we were stronger in the sense of being more complete. By contrast our present situation represents a 'fall'. The sole problem was human hubris. 'We desired, in what may be called the pagan version of Original Sin, to overthrow the gods' (Hyland 1995:113). To punish us Zeus split us into two beings, knotting the skin at the navel so when we look down it will remind us of our former glory and move us to humility. Of course, at the same time Zeus doubled the number of human beings, thus increasing the supply of offerings to the gods. The god Eros was also born to this divided fallen state. He has three 'elements'. The 'ontological' element is the imperfect, incomplete human condition. People are erotic but incomplete. The second element of Eros is recognition of the incompleteness, and the third the striving to surmount it by reverting to the original state of fulfilment (completeness). That explains our comical attempts to unite sexually with our other half:

We take all those funny positions and get so passionately excited because we want to overcome our physical incompleteness and become whole again ... In principle, all the myriad ways in which we are incomplete, experience that incompleteness, and strive to overcome it, are manifestations of our erotic natures.

(Hyland 1995:115)

Plato's Symposium tells Socrates's story of his experience with Diotima to explain the nature of love (Eros). Eros cannot be divine, because he is composed of opposing entities. His father, Poros, the God of plenty, was seduced by Penia (poverty). Because of his parentage he is alternately poor and rich, oscillating between affluence and penury, wisdom and folly. Here Eros symbolises desire, which always oscillates between fulfilment and unfulfilment. This is typical of human beings, who not only oscillate between want and abundance, but remain unsatisfied even in times of plenty and, like Eros, constantly strive for fulfilment, as evidenced by the history of eroticism in human life (see Du Toit 2010:65-67). Thus humans were destined for eroticism, for incompleteness from the outset, and they are aware of it. They are not responsible for their sense of incompleteness and unfulfilment, nor can they control it - it is a result of the 'original $\sin ^{\prime}$ of their ancestors. Secondly, they cannot but try to surmount their incompleteness; and thirdly, they are doomed to failure (Hyland 1995:118). Aristophanes sees the manifestations of Eros as polysemous: the creation of laws, artistic creativity, philosophy, all the noblest human aspirations. In this sense Eros also offers comfort (Hyland 1995:121, 123).

Thus self-transcendence may be seen as erotically driven, for it suggests:

10. Here I follow Hyland's version (1995:111-137), which focuses on tragedy and comedy in philosophy. 
that behind action lies dissatisfaction with what one has, desire to have something else; behind going lies not wanting to be here, wanting to be there. From the standpoint of the agent 'there' is better, 'here' is worse.

(Barabas 1977:178) ${ }^{11}$

Even though the driving force of self-transcendence is desire, we cannot conceive of life without it. Without desire the world is tedious. An example is Ulysses's rejection of Calypso's offer of immortality: he prefers the excitement of being human to the boring perfection of the gods. 'Here deathlessness and agelessness don't mean divinity but the never-endingness of hell' (Barabas 1977:182). Voltaire's Candide is equally bored in the perfect Eldorado, where nothing is lacking except the thrill of desire (Du Toit 2007:269). ${ }^{12}$

In the final analysis, the paradisiacal harmony described in myths of origin is as unending as desire. ${ }^{13}$ The Old Testament story of the Fall presupposes a paradisiacal state, but who really knows what that was? The notion of paradisiacal bliss, like the notion of infinity, can only be understood in terms of human experience of need and desire. Poros's abundance is as infinite as Penia's want. Perfect harmony in its infinitude is unknowable. Plato connects Eros with the idea of creation and, as Paul Riceour (1986:13) states, creation entails a dual infinitude: 'All things emerge from nothingness and are borne toward the infinite'. The same applies to any science that grows from the nihil of genesis. This mixture of finitude and infinity, of fulfilment and unfulfilment characterises the development of thought from mythos to logos. Logos does not mean unadulterated, unequivocal truth. It is never free of myth. That is why it resorts to metaphors, models and analogies, all strategies indicating that we do not fully know.

Sin reinterpreted in the foregoing way is crucial for our notion of transcendence as expounded here; it is vital if religion is to retain its allure. The next section probes this aspect, explaining why human beings must be viewed as open and unfulfilled. The situation is indeed one of non posse non peccare.

\section{Christianity's relative disregard of desire and infinitude as essential to the human self}

The same elements of desire, separation, sin, an original state of harmony and nostalgia for it, and infinitude (immortality) feature in the Christian doctrine of the Fall. Desire underlies the fall. Eve finds the tree of knowledge of good and evil desirable (Gn 3:6). The result is separation (from paradise, God, eternal life, humans' true self as the image of God).

11.Nancy (2002:60) sees self-consciousness as desire: 'Self-consciousness is essentially desire, because it is consciousness of self as and out of its consciousness of the other.'

12.The erotic drive, marked by separation, unfulfilment and infinitude, is obviously rooted in physical sexuality. But it would be reductive to limit it to that, since it is basic to the entire human psyche. The popular distinction between Eros and agape is misleading, because Eros is not devoid of agape, and vice versa.

13.That is why myth is the apposite idiom for speaking about fulfilment and unfulfilment. If we shift from myth to logos, we get bogged down in the paradoxes that often characterise metaphysics.
Martin Buber (1939:229) puts it aptly: 'Through the Fall the unity of being and destiny, or of the "I" and the "Self" has been lost. Hence sinful man is forced continually to seek his Self or himself.' Buber considers humans to be self-contradictory (the original title of his book was Der Mensch im Widerspruch). They rebel against God, against their divine destiny (Buber 1939:169, 171). They cannot return to their perfect origin and each day brings a fresh fall. Human conflict is enacted in the stress-field between our human sinfulness and the image of God in us (Buber 1939:172,174). Transcendence is intrinsic to humanness:

Man contrasts the imperfect world of actual experience, as he knows it, with a perfect existence, a heightened, intensified, ideal existence, freed from the contingent and accidental, the sight of which gives him a satisfaction which is wholly different from that of the experience of any reality in this world as it is.

(Buber 1939:175)

That is the 'infinite' in human beings (given with consciousness) and that is why nature or finitude fails to satisfy us. 'We long for simplicity, for that which is wholly natural. But is seems as though man, and man alone, were condemned never to find the simple and natural' (Buber 1939:183). Buber rejects recognition of the natural, biological dimensions of humanness as materialism, which he defines as follows:

Essentially man is an animal, his instincts as well as his physicopsychical organism are the same; the only difference is that through the special development of his brain and of the central nervous system the life-process gains new possibilities of differentiation. It is from such differentiation that 'culture' is to be understood, as superstructure - biologically necessary - of the vital functions. The spiritual element serves to regulate the life of this highly developed animal, and to keep its course as even as possible; owing to the special character of this animal, it needs these special measures to protect it.

(Buber 1939:189)

In Buber's view the Platonic myth of the Fall is caused by our sensory nature. He repudiates the notion that human conflict is the result of that nature rather than of the human spirit:

The spirit is victim of the delusion of the senses. Thus this view is not dealing with an actual contradiction, defiance, rebellion of man against the Creator, but with an unfortunate combination of the elements of which human nature is composed.

(Buber 1939:193)

In this, Buber (1939:198) acknowledges that humans are Eros, which he associates with reason and spirit, but traces it all to the classic conception of the Fall.

Here Hegel's argument remains the most plausible, because unlike Buber (and most theologians of his time), he does not denigrate natural explanations. Hegel (1985:92ff) deals with the Fall under the heading of "Alienation": Natural humanity'. He accommodates human biological nature in the functioning of the human spirit (mind). Human nature is not evil in itself - that would be a Manichaean dualism:

Rather it is when human being constitutes its existence, establishes the criteria for its life, according to the immediacy, particularity, and externality of the physical nature it shares with all created things, that 'cleavage' occurs and evil arises.

(Hegel 1985:92, n.90) 
The notion of the Fall and sin is a consequence of human nature as possibility ('original state') and the movement to immediate circumstances, of human self-consciousness which is not what it should be (Hegel 1985:95-96). We have the potential (for development, insight, understanding) but Spirit has not yet developed sufficiently to realise that potential fully. The notion of an original state is the representation of humans as the image of God (Hegel 1985:96). Philosophically it is:

a condition of the highest spiritual perfection, of a human being in unity with nature, hence as an untroubled intelligence, which does not turn away from nature into itself by means of reflection, an intelligence that penetrates nature as its spiritual centre, yet not by standing over against it or separating from it, but as an intelligence that exists as a pure and highest knowledge.

(Hegel 1985:97)

This primal state is based on affect, instinct and intuition and is not yet governed by reason (Hegel 1985:98). It is thought that gives rise to the host of ideas and thus to the multiplicity and separation with which we live.

Evil, then, has to do with our contingent circumstances (with the accent on individual aspects such as personal need, want, desire) and what emerges from our mental processes (cognition, representation, volition):

Both good and evil are before the human being; it has a choice between them, and its will is evil. Hence evil is its fault [Schuld]. This evil is self-seeking: its goals relate only to its singularity insofar as it is opposed to the universal, i.e. insofar as it is natural ... In a purely abstract natural condition, humanity is neither good nor evil; this means however, that it is not yet actually human ... Thus evil, the will of self-seeking, exists only through consciousness and cognition, and constitutes the first form of will.

(Hegel 1985:102-103)

Hegel uses this background to put the biblical Fall in a new perspective. He points out the contradictions in the story. Humans are forbidden to eat the fruit of the tree of knowledge of good and evil, yet this knowledge is what distinguishes the human mind from that of animals. The snake promises that eating this fruit will make humans like God (sicut Deus), yet even before they tasted the fruit God had said that they 'had become like one of us' (Gn 3:22). God himself acknowledges that the divine in human nature is a product of knowledge (both generally and knowledge of good and evil) (Hegel 1985:104-105). Hegel links this with his basic model:

For the speculative content is precisely the comprehension of the concept of the thing - which involves the concept's development - and hence the comprehension of the inner antithesis that the concept contains and through which it moves

(Hegel 1985:105)

Thought is not possible without a negative, a contrast, and myths of origin are no exception. That is why they are always marked by separation, opposition and the infinite. The question of good and evil is unavoidably part of our thinking and any contradictions must be resolved by that same rationality. Thought both wounds and heals itself! '[It] is not that it [sin, evil] ought not to occur: it has occurred because human being is consciousness' (Hegel 1985:106). Humans are banished from paradise because of knowledge (leaving animals better off!). Originally they were immortal, so why eat the fruit to gain immortality? But the myth is meant to explain mortality as a result of human finitude (Hegel 1985:107). Hence the human mind comprehends the idea of finitude and infinity, of divinity and humanity as part of its substance:

This infinite possibility is its subjectivity. In this consciousness humanity knows the divine idea, the universal, and knows itself to be determined for the universal, i.e. elevated above all locality, nationality, condition, life-situation etc.

(Hegel 1985:109)

If we apply this to encounter with God, the radically transcendent, we cannot bypass ordinary thought processes. Revelation does not present a Deus nudus but a mental turning point. ${ }^{14}$ By the same token, the search for a 'true' self via self-transcendence can be experienced as intensely meaningful. The act of self-transcendence is our attempt to understand ourselves at a given moment by seeing ourselves 'in terms of...', 'in relation to...' or 'as responding to...' - but also by experiencing ourselves as 'more than...'15 'The I is not a being that always remains the same, but is the being whose existing consists in identifying itself, in recovering its identity throughout all that happens to it' (Levinas 1979:36). The self, like God, is infinite and all other aspects of self-experience are part of our mental processes. We speak about the self emerging in language, ideas and experience without abolishing its 'alterity' (otherness). Through selftranscendence I attain enlightenment and understanding without fully 'clarifying' myself. ${ }^{16}$ The finite cannot know the infinite, yet we 'know' ourselves and believers intuitively 'know' God. Desire is insatiable, but that does not prevent ongoing interaction with the object of desire. It is a possible impossibility, a transcendent experience, a paradox of consciousness, a perpetual self evaluation. The nature of the human mind and its concomitant thought processes (which entail concepts like infinity, unknowability of the Ding an sich) cannot but impose a perennial character on the sciences, from philosophy, epistemology and psychology to physics. ${ }^{17}$ The Kantian transcendental subject, via transcendental imagination, produces syntheses and mental constructs

14.One cannot reflect on God without reflecting on humans as transcending and selftranscending beings. Dupré (1976:viii) writes: 'The word "God" appears on every page of Western philosophy. Yet rarely do we find mentioned the inner space out of which the idea of God grew and developed. Instead we encounter mostly out of which the idea of God grew and developed. Instead we encounter mostly descriptions of an ultimate reality, opposed to the self's being and separated from it in a "supernatural" realm of its own.' One reason for this is probably the tradition of objectivity that dates back to the ancient Greeks. Dupre (1976:33-34) mentions that the notion of self first emerged in Hellenistic and Roman time when the bonds between the individual and society were loosening - a proces completed by Christianity. 'Thus transcendence came to occupy the very centre of self-awareness.'

15.With reference to the relevant authors Hankiss (2006:204-205) lists 41 definition of self. The many examples (only well-known authors are mentioned) include: the self as noumenal or phenomenal, transparent, Faustian, implicit, schizophrenic post-self, self-deceptive (Rorty), extended, created (Weber), creative (Maslow), embodied (Kristeva), disenchanted, symbolic, normative, problematic, changeable, minimal, marginal, evolving, transcendent, pre-linguistic, semiotic, and so forth.

16. Here I follow the distinction made by Caputo and Vattimo (2007:81-82) between world and event: 'Thus instead of opposing two worlds, or of opposing God and the world as if these were two realms of being, I distinguish between the world and the event by which the world is disturbed, the unconditional claim that solicits the world from within, that interrupts and summons it, which I think deconstruction
is (if it is).'

17.For the phenomenon that knowledge is increasingly regarded as mystery, see Du Toit (2007:155-156). 
that are not empirically observable. We experience these as consciousness of knowledge. But 'synthesis' comes at a price: 'As soon as reflection comes on the scene it sunders man, for reflection is essentially dividing, sundering' (Ricoeur 1986:19, 1992:339). The synthesis seeks to connect my inner mental world with the outside world; hence, rationality is marked by the same separation as Aristophanes's myth of origin. The diverse rational models are no less comical than the postures Aristophanes ascribes to our attempts at achieving perfect union. The separation between subject and object, self and other occurs via human corporeality in the mode of receptiveness. Openness to the outside world is prerequisite for knowing anything and any knowledge I have is always from my particular perspective: 'Primal finitude consists in perspective or point of view. It affects my primary relation to the world, which is to "receive" objects and not to create them" (Ricoeur 1986:24). Perspective is simply the angle from which I observe things. Our finitude is determined by our slant on reality. There are many possible perspectives, of which mine is but one. No person or agency can accommodate all possible points of view. My outlook is always finite. The totality of possible perspectives is endless, for there can always be new ones. Our finitude is also emphasised by the fact that we cannot fully express our meaning in language. Moving from myth to logos does not imply that logos represents ultimate or authentic truth. Thus Ricoeur (1986:30), referring to Hegel, writes: 'We do not actually and absolutely say what in this sense-certainty we really mean.' Reason is doomed to perpetual transcendence. To Ricoeur (1986:43) the distinction between sensory experience of things that manifest themselves and an attempt to grasp and articulate them intellectually is not solved by a philosophy of finitude, even of self-transcending finitude. It needs a synthesis that links finitude with rationality (including universality and infinity):

If man is a mean between being and nothingness, it is primarily because he brings about 'mediations' in things; his intermediate place is primarily his function as a mediator of the infinite and the finite in things.

(Ricoeur 1986:46)

It is via transcendental imagination (the third term) that humans are able to link understanding and sensibility (Ricoeur 1986:73). Transcendental imagination is the hidden synthesis that constitutes the form (understanding) of things (Ricoeur 1986:79ff).

\section{Desire, distance, infinity and the other}

This section highlights the positive aspect of desire and infinitude. The force driving me towards the future can obviously be either negative or positive, but it is certainly not exclusively negative as Christianity would have it. I also look critically at rationalism and unitary (totalitarian) thinking, which leaves no scope for transcendence. At best it separates transcendence dualistically from rational immanent reality. I also focus on Levinas's location (Platz) of transcendence in the face of the other, which inevitably introduces an ethical dimension. Unfortunately he fails to point out that seeing transcendence in the face of the other cannot be taken for granted, any more than the experience of transcendence within the self or in events around us.

In the foregoing model, desire, separation and the infinite are metaphysically interconnected; hence, the 'object' that arouses my desire is necessarily marked by infinitude. Levinas $(1979: 50,62)$ sees desire as 'the Desire for the Infinite which the desirable arouses rather than satisfies'. To him the difference between desire and need is that desire is aroused by the other (her face), whereas need centres in the subject (Levinas 1979:62). We can satisfy a need, but not a desire. His view of desire is positive. It is insatiable for the very reason that it is not a matter of need satisfaction but of the infinite, the other: 'Immortality is not the objective of the first movement of Desire, but the other, the Stranger. It is absolutely nonegoist; its name is justice' (Levinas 1979:63).

To Levinas (1979) the hallmark of metaphysical unitary thought is that separation is unacceptable and must be seen as a fall, privation or temporary rupture of unity - separation is regarded as need:

Need indicates void and lack in the needy one, its dependence on the exterior, the insufficiency of the needy being precisely in that it does not entirely possess its being and consequently is not strictly speaking separate.

(Levinas 1979:102)

What makes Levinas's work remarkable is his criticism of the Western ontology of power and his replacement of egocentric substantialist thought with the dependence of relationality (relationship with the other). This is achieved by shifting the emphasis from totality (unity) to infinity (separation), which makes everyone dependent on infinite desire for the other; hence enabling them to elude the stranglehold of knowledge.

Thought is governed by finitude and infinity. ${ }^{18}$ To Levinas infinity $^{19}$ is inherent in humanness: it is what inheres in my self 'as a positing in $m e^{\prime}$. 'The distance between me and God, radical and necessary, is produced in being itself' (Levinas 1979:26, 48). Levinas is opposed to Western unitary thought ${ }^{20}$ and replaces unity or totality with infinity, as reflected in the title of his Totality and infinity. Infinity manifests itself in alterity, which human beings desire: 'It is understood as the alterity of the Other and of the Most-High' (Levinas 1979:34). He refers to a transcendent metaphysical movement, 'and transcendence, like desire and inadequatio, is necessarily a transascendence (Levinas 1979:35). The notion of an ascending movement has to do with the infinite that manifests itself in me and makes me move beyond myself

18.This idea derives from Hegel: 'How spirit is the finite that finds itself to be infinite in the exposition of its finitude, this is what is to be thought - which is to say, this is what it is to "think"' (Nancy 2002:31). Hegel (1959:89) links infinity and finitude: 'Thus the failure of all rational theology is clear: It is unable to see that a dialectical negation is also an affirmative relation. If infinity is thought by itself, apart from the finitude of the existing world, then infinity itself becomes something finite; it is limited by the otherness of the world.

19.We do not know what infinity means. The concept modifies our experience of finitude. That does not mean we can do without it, any more than we can do without 'nothingness' (non-being) and negativity, which serve mainly as catalysts of thought.

20.Unitary thinking as a metaphysical motive extends from Parmenides and Plotinus to Spinoza and Hegel. To Levinas (1979:102) the gist of it was that 'separation and interiority were held to be incomprehensible and irrational. The metaphysical knowledge which puts the same in touch with the other then would reflect this knowledge which puts the same in touch with the other then would refle
falleness. Metaphysics would endeavor to suppress separation, to unite'. 
towards the other. This movement towards the other is not like a mental movement when I approach some object. The other is not an object. That is why Levinas (1979:49) makes a clear distinction between transcendence and objectivity and criticises Western ontological thought, which he regards as a philosophy of power that dominates the other (Levinas 1979:45-46). ${ }^{21}$

Although human finitude may be experienced negatively, Levinas does not see the experience of finitude and negativity as the driving force behind human transcendence. 'The idea of the perfect and of infinity is not reducible to the negation of the imperfect; negativity is incapable of transcendence' (Levinas 1979:41). The notion of infinitude includes separation, symbolised by distance. Infinity always lies ahead of me; I do not coincide with it, which implies separation of finite humans from infinity. We find that separation within ourselves, in our unconscious, creating distance between me and my self, ${ }^{22}$ but also between me and others. ${ }^{23}$ Separation is a product of thought. Infinity is inconceivable if I do not exist separately from others (Levinas 1979:54, 79). Because humans are separated from others outside themselves they can elevate themselves to an absolute point of reference. Levinas (1979) sees absolute separation as nonrelationship, introversion into the self and hence atheism:

One can call atheism this separation so complete that the separated being maintains itself in existence all by itself, without participating in the Being from which it is separated ... The soul, the dimension of the psychic, being an accomplishment of separation, is naturally atheist. By atheism we thus understand a position prior to both the negation and the affirmation of the divine, the breaking with participation by which the I posits itself as the same and I.

(Levinas 1979:58)

That is symbolised by desire. Whereas desire is occupied with the other, the search for happiness is occupied with self. That is why he compares happiness with politics (the search for power) and desire with religion, for:

religion is Desire and not struggle for recognition. It is the surplus possible in a society of equals, that of glorious humility, responsibility, and sacrifice, which are the condition for equality itself.

(Levinas 1979:64)

Normally we are unaware of our own transcendent orientation and the transcendent (unknown) dimension in other people, things and events is overlooked and disregarded, because we reduce them to our fixed ideas. ${ }^{24} \mathrm{We}$

21.This includes the 'objectivity' of self-knowledge: 'The subject is "for itself" - it represents itself and knows itself as long as it is. But in knowing or representing itself it possesses itself, dominates itself, extends its identity to what ... itself comes to refute this identity' (Levinas 1979:87)

22.Ward (2007:123) puts it thus: 'Perhaps the closest we get to distance as such is the identification of difference. This distance is implicated then in a common participation, a common recognition of exteriority: I am not the other; the other is not $\mathrm{I}$; the other is not reducible to or measurable by me; and I am not reducible to or measurable by the other. What is intimated in this distance is an excess; the mystery of alterity. Every representation made in this distance must fail if the aim of such representation is to define.'

23.Frandsen (2007:115) formulates the same idea thus: 'We can see it in the way that man, in the very moment he discovers his "interior" as something originary, and so takes himself into possession, also and at the same time discovers that this" "the most proper" in advance is in relation to some "other" or to some "exterior", to a transcendence that qualifies the "internal man".'

24.The reductive process that confines the infinite other to race, gender, identity, et cetera usually manifests as binary thought (see Du Toit 2004a:442-459). ascribe identity, characteristics and attributes to people and gods to give us control over them. We want to know whom we are dealing with and what to expect from them. We want to secure ourselves. We want rules to regulate our interaction with people and things. They are necessary for a structured society, so we pin people down to perceptions. To facilitate the process we classify them according to race, gender, class, culture, literacy, characteristics, and the like. For ourselves we claim the luxury of 'openness', self-transcendence, the desire to realise some ideal without being pinned down to particular words or actions. But encountering the other in her infinitude makes this impossible: 'The face resists possession, resists my powers. In its epiphany, expression, the sensible, still graspable, turns into total resistance to the grasp' (Levinas 1979:197).

Hearing the divine word is not the same as knowing it as an object. It is more like opening up to something different, achieving an encounter, initiating events. Levinas hears God's voice in encounter with the other:

The dimension of the divine opens forth from the human face. A relation with the Transcendent free from all captivation by the Transcendent is a social relation. It is here that the Transcendent, infinitely other, solicits us and appeals to us. The proximity of the Other, the proximity of the neighbor, is in being an ineluctable moment of the revelation of an absolute presence.

(Levinas 1979:77-78)

Not that God is incarnated in the other, 'but precisely by his face, in which he is disincarnate, is the manifestation of the height [read infinity] in which God is revealed' (Levinas 1979:79). And: 'If I can no longer have power over him it is because he overflows absolutely every idea I can have of him' (Levinas 1979:87).

The other's infinitude makes relationship possible (Levinas 1979:196). The face and the affects it expresses are always complemented by appropriate dialogue ${ }^{25}$ :

Theidea of infinity is produced in the opposition of conversation, ${ }^{26}$ in sociality. The relation with the face, with the other absolutely other which I cannot contain, the other in this sense infinite, is nonetheless my Idea, a commerce ... the face speaks to me and thereby invites me to a relation incommensurable with a power exercised, be it enjoyment or knowledge.

(Levinas 1979:197, 198)

The other enhances my freedom, for instance by evoking my goodness: 'The face opens the primordial discourse whose first word is obligation, which no 'interiority' permits avoiding.' It is the infinitude of the other which generates ethics (Levinas 1979:201, 204).

Desire is tied up with the other. It also includes the other's desire. ${ }^{27}$ My self does not coincide with the self of the other. It

25.Levinas does not elaborate on this. Today we know that the so-called mirror neurons evoke emotions that we perceive in us as well. Emotion evokes emotion in a widening spiral. Only rational intervention can temper unbridled emotion. But in a widening spiral. Only rational perervention can temper unbridled emotion. But affect and reason (discourse) should complement each other. That is the weakness of over-emotional sermons that usually lack substance. Conversely, overly rationa
sermons that do not address us emotionally are no more than lectures.

26.Levinas (1979:206) refers to the 'primordial face to face of language'.

27.'The I, in conflict with its immediate practical existence (Dasein), is both individual and social. Every practical self is in the same situation, recognizing in the other the same problem which is in itself. The object of desire thus changes and becomes another I. Each I wants to be one with and recognized by another I; concurrently, each I remains an independent individual, an alien object for the other' (Hegel 1959:215). 
is desire that the other will recognise me as the desire I am, as the infinite self-becoming that I am (Nancy 2002:62). The self is desire. Nancy (2002) describes it thus:

Desire is the necessity of consciousness: it is the necessity that the unity of consciousness come and become for consciousness itself. Desire is therefore less the tension of lack, and the projection of a satisfaction that would annul it, than it is the tension of the coming of the other as the becoming of the self ... Desire is neither aspiration nor demand, nor is it lust or voracity. It demands nothing but the other, and is satisfied with nothing other: but the other as such, the veritable other of the self, is not an object one could demand, an object with which one could take satisfaction.

(Nancy 2002:61)

\section{The 'self' in self-transcendence}

Augustine, pioneer researcher of the inner world of human thought and conscience, distinguishes between se cogitare (to think about oneself) and se nosse (to know oneself) (Dalferth 2007:45). Knowing oneself is knowledge of 'movements' of the self rather than of a fixed core. The pursuit of self-knowledge often leads to self-conflict. Levinas (1979:37) puts it thus: 'The I that repels the self, lived as repugnance, the I riveted to itself, lived as ennui, are modes of self-consciousness and rest on the unrendable identity of I and the self.' Hence I am a stranger, an other to myself (see Levinas 1979:39).

What is the mental world of the divided subject like? It is characterised by the unknown (transcendent) nature of the other and oneself. It is, in effect, the dimension of infinity that we attribute to self-knowledge and knowledge of the other. Because we can never know completely, the process of knowing is itself a never ending, ever unaccomplished labour. To the extent that it is successful, my self-knowledge does not imply transparent self-knowledge on the part of the other to whom I am relating. But neither am I transparent to myself and the ego I 'actually' am remains an enigma to me. ${ }^{28}$ There simply is no single 'core' I or transcendent I behind my thinking, language and behaviour, who rules the dream world of the unconscious like a demiurge and then surfaces at the conscious level. ${ }^{29}$ To understand myself in my self-transcendent mode I have to realise that I am never fully accessible to myself (Dalferth 2007:46, 48).

The concept of a transcendent self refers to the mysterious, even unfathomable and inexplicable aspects of self. It refers to the enigma of the unconscious, the unknown, Lacan's objêt petit $a^{30}$ the transcendental imagination that is only known

28.I am simply not aware which experiences from the past influence my current perceptions (especially my emotions). Hegel (1959:203-204) describes it thus: 'The soul is in tension: On the one hand, it is a subjective centre for itself and on the sour in it remains tied to a vast subonscious substantial life. I a simple the other hand, it remains tied to a vast subconscious substantial life. I am a simple, bottomless pit sunk into an infinite abundance of possible or virtual experiences The individual never knows how many experiences have been experienced and all its functions, the soul is a monad: It carves out of its experience the totality of a particular world-view in which it mirrors itself.'

29.This does not mean that we cannot assume various 'roles': 'Theatres will never be able to compete with the wealth of roles played by people in their everyday lives' (Hankiss 2006:313, n.34).

30.Žižek (2006:67) defines Lacan's concept of objêt petit $a$ as both the object and the cause of desire. The cause of desire always exceeds its object: ' $\mathrm{No}]$ matter how close I get to the object of desire, its cause remains at a distance, elusive" (Žižek 2006:77). Applied to desire it means that I desire the other's desire, so desire itself becomes an indeterminate drive (Žižek 2006:42). Hence desire can be seen as perpetually transcendent. That is why Freud's work is equally dualistic: on the as perpetually transcendent. That is why Freud's work is equally dualistic: on the one hand cognisance of our physical apparatus, on the other the hermeneutics of the of the tongue (Žižek 2006:77-78). when it happens, desire that always exceeds the desire for demonstrable objects, one's alter ego, the unexpected voice of conscience, et cetera. Neither does the transcendent I have an 'identity', for then it can be known, be pinned down. The transcendent I manifests itself (an epiphenomenon like consciousness) in what happens.

The same applies to the question of which self is transcended in self-transcendence. After all, the self is not a fixed entity that remains the same (idem). In the mode of self-transcendence, self (ipse) does not coincide with the self that I or others construe. Hence it is not self in the idem sense of the word. ${ }^{31}$ If I as a self is characterised by transcendence, we can assume that the other selves (my Gegenüber) that make up my world are similarly structured. The other's transcendent nature makes knowledge of the other no less complicated than selfknowledge. It is primarily the way the $\mathrm{O} /$ other features in our consciousness that creates awareness of transcendence, because my self never coincides with hers (Ryle 1949:16-17).

But clarifying the self does not necessarily affect our experience of ourselves. For example, we do not experience ourselves differently after studying brain scientists' explanation of self-experience. ${ }^{32}$ One may surmise that advances in the cognitive and brain sciences will afford greater insight into the biologically structured background to humans as 'open', hence self-transcending beings. But even such insight into our biological functioning, especially that of consciousness, does not alter the fact that we cannot live outside our bodies, our consciousness or our brain structures. That is because thought always rises above physicality, even though it is wholly dependent on it. My thoughts emerge from the diverse operations of my brain, yet what I think is not determined by the physicality of my brain but is, at most, made possible by it. That has to do with the distinction between the brain and the mind, an epiphenomenon of brain, which is completely dependent on it but at the same time 'exceeds' it. I am my own understanding (Dalferth 2007:48). 'Being reasonable is trying to overcome our first-person perspective by being neutral, not partial, and open-minded. Reason must govern reflection, and reflection overcomes first-person perspectives' (Dalferth 2007:49).

The human self is never neutral but is always preoccupied. As a rule, the self is seen in terms of a relation to some ideal, problem, need or lack and one's identity at a given moment is determined by that interaction. But our selfconsciousness 'integrates' all aspects of existence and thus

31.This is set forth mainly in Ricoeur's Oneself as another (1992:115ff).

32.Self-consciousness is not exclusively biologically determined, otherwise we would still think exactly as our ancestors did. Our brain processes are no different from those of Cro-Magnon man, but we do not think the same or experience ourselves and our world in the same way. That is because our biology is only part of the story and the interpretive 'how it works' of the brain sciences tells us nothing about the and the interpretive "how it works' of the brain sciences tells us nothing about the what and the why of present-day brain contents or about experiences and ways of expressing self-transcendence. An example is human emotions: 'The emotions of human beings the world over are as innate and as constitutive and as regular as ur bone structure, and ... this is manifested in the universality of ways in which we express them' (Walton 2004:xiii). But the things that people find shameful, what they fear and what makes them happy varies from one culture, era and person to
the next. 
effects a holistic, 'unified' sense of self. ${ }^{33}$ That sense of unity creates the impression of an 'isolated' core identity, in terms of which contingently changing self-perceptions should be interpreted. The self is an ongoing construction determined by our contingent being-in-the-world (Dasein). At a given moment, we do not have an array of diverse self-experiences before us, like childhood photographs that we can compare to determine differences and similarities. We only remember highlights and mentally associate changes of identity with these.

Hence self-transcendence does not entail a complete blueprint, a self approaching the outside world as a fixed identity. Self-perceptions are always from a particular perspective. So what the 'self' in self-transcendence actually consists of complicates the issue. ${ }^{34}$ It is not immutable, exactly defined or fixed. ${ }^{35}$ The 'self' that is transcended is, at most, a particular facet of our self-experience at a given moment. ${ }^{36}$ Humans are designs-in-process to the day of their death. Human identity is continually changing, because it emerges every day in a particular challenging context in a unique manner. Self-transcendence merely reflects our intentional structure: we are schemers, forever moving from some state of incompleteness or unfulfilment towards change and a remedy for that state - be it physical (illness, poverty), epistemological (ignorance, error), social (poor human relations), political (oppression, unfreedom), religious (sin), ethical (absence of goodness) or psychological (some kind of 'pathology'). It is expressed by the narrative self. ${ }^{37}$

The focus on the interior world, like metaphysical ontotheology, is biased. One has to link the quest for the transcendentally mysterious interior world with the reality of

33.Poststructuralists have criticised philosophies of consciousness or the subject along with structuralism for introducing a new dualism: 'Structuralism operates, as we have seen, on the basis of qualitative phenomenological oppositions and dichotomies such as small/large, male/female, odd/even, appearance/reality, false/true, and philosophies-of-the-subject on the basis of differentiations alse/true, and philosophies-of-the-subject on the basis of differentiations between subject/object, scheme/content, intention/reference and so on' (se anz 2004:34). The question is whether it centres on the integrity of human subjectivity or is striving for some totality and unity. I assume that the same physically determined human brain permits the epiphenomenon of thought, which throughout all distinctions and self-definitions that occur remains a single movement that inevitably discriminates between various schemes, some of which may appear to be dualistic.

34.The self can be explained from the perspective of language, rationality, existence the unconscious (psychoanalysis), human biology (brain sciences). The framework in which human identity and self-understanding is viewed is usually reductive, because no single aspect of human nature in isolation can explain all other facets.

35.By the same token, the ancient Greek maxim, 'know yourself', is not a programme of self-knowledge and self-improvement, but expresses a belief that an unscrutinised life is not worth living.

36.I do not dwell on Foucault's notion that the self is a construction, nor on the Buddhist concept of the illusory self (see Du Toit 2004b:1-45). Some structuralists also deny the existence of an autonomous human self and regard it as a conglomerate of structures. Others (e.g. Nikolas Rose) see the language of a particular historical structures. Others (e.g. Nikolas Rose) see the language of a particular historical
era as a confined space (prison), in which any configuration of the self is possible. era as a confined space (prison), in which any configuration of the self is possible.
Hankiss $(2006: 92-93,95)$ points out the role of consumer society and advertising Hankiss $(2006: 92-93,95)$ points out
in constructing the present-day self.

37.The story we tell about ourselves (narrative self) is constructed by the imagination that transforms diversity into identity (Ricoeur 1992:127). It is our conception of our 'character' which compels us to see identity as sameness (idem) (Ricoeur 1992:128). The narrative self is determined by the way we link self and events (Ricoeur 1992:142). Ricoeur (1992:159ff) applies the strategies of a novel to the narrative self. Regarding the relation between author, narrator and characters, he maintains that in my the characters, he mystains that in my owh story myself at most as co-author, because other influences in the story also play a role.

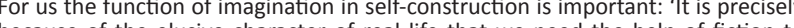
because of the organize life retrospectively, after the fact, prepared to take as provisional and open to revision any figure of employment borrowed from fiction or from history (Ricoeur 1992:162). the outside world.$^{38}$ However unique or enigmatic the inner world, it can never be divorced from the external world. Selfunderstanding is not a purely private business but a public enterprise. Consciousness itself is densely populated by the actors and plots that make up the theatre of the mind. Although contingent reality is forever changing, it remains my frame of reference for every self-evaluation.

\section{Role of affectivity in objectivity}

The subject enters the outside world (with intentionality, will and desire), but also receives it (as a gift, an appeal, enigma and challenge). The way we perceive the outside world depends on the mental lens we are using at that point in time. The lens diminishes our expectation and intention. But reality rarely fits into the lens and we are constantly forcing new focuses into our field of vision. If double vision sets in or our view is out of focus, conflict arises, which assumes diverse forms. It is given with desire as an existential mode, in which fulfilment continues to elude us.

Naturally, affectivity accompanies every relation with the outside world. 'Affectivity, an intrinsic dimension of embodiment, is itself intimately linked to a primordial interest, orientation or motivation, animating movement, perception and thought. Affectivity always permeates the cognitive stance' (Parnas 2007:62-63). Affectivity is a neglected aspect of all epistemologies in our rational, modernistically oriented society. That is because our epistemological models focus on what can be rationally articulated. At most, affectivity features passively in the framework of logical, rational propositions. Rationality is marked by control; when we rationalise something we are in control. But we do not control our emotions - they control us. Emotions are not consciousness, but they inform consciousness. In that sense human affect, like consciousness, has an infinite dimension. Desire evokes affects (jealousy, contempt, happiness, unhappiness). Fear, especially in the form of anxiety, has to do with the unknown. Longing and nostalgia presuppose distance and separation. Our experience of transcendence may be marked by emotions like surprise, fear, guilt feelings and the like.

Consciousness is always co-determined by emotion, although as a rule it is 'neutral'. I cannot decide what mood I want to be in and then it happens. Emotion is the stepchild of the public, rational self. It is the embarrassment of our corporeality, our biology. Yet is emotion not where we are closest to our bodies? That is why we usually confine it to our private space and do not admit it to the daylight of reason. Emotion is the embarrassing fear, jealousy, contempt, pride, admiration, nostalgia informing our rational perspective. It is also the dark area where desire, imagination, intuition and creativity lurk - without which no innovative thought

38.Wider (1977:152) cites Edelman's theory of different neural and cognitive maps that determine how the external and interior worlds feature in the mind. This means that input from both self and the world are necessary for consciousness. He distinguishes between primary consciousness underlying a higher consciousness. It is not personal and does not require language. Here self refers to automatic It is not personal and does not require language. Here self refers to automatic
processes that are necessary for individual self-preservation. It calls for both present and past perceptual categories of self (Wider 1977:140). 
is possible. To us, it is the often irrational and embarrassing limbic system, which nourishes the 'disembodied' sphere of the rational, thinking self that is 'isolated' from us.

Affectivity determines every epistemology as well as all self-understanding. ${ }^{39}$ In a sense, epistemological inquiry into knowledge, the role of transcendental reflection in knowledge, the relation of subject to object and the like remain formal and abstract. It does not involve affectivity, practicality (ethos) and the axiological aspect of human knowledge. Feeling and knowing are interdependent. 'Knowing ... exteriorizes and poses its object in being, sets up a fundamental cleavage between the object and the subject. It "detaches" the object or "opposes it" to the I' (Ricoeur 1986:85). Whereas knowing establishes the duality of subject and object, feeling overcomes it. 'Feeling is ... the manifestation of a relation to the world that constantly restores our complicity with it, our inheritance and belonging in it, something more profound than all polarity and duality' (Ricoeur 1986:85). When we attribute feelings to objects (it is desirable, repellent) we appear to be dealing with objective qualities. But they are not qualities that confront the subject like objects - they are rather the intentional expression of a unifying bond with the world. I am affectively present in the world. That is why Ricoeur calls feeling the colour of soul: 'It is the landscape which is cheerful, and it is I who am elated' (Ricoeur 1986:89)..$^{40}$

If paradox, separation and the finitude-infinity conundrum are part of objective knowledge, they are all the more so when we take into account their affective aspects, where the focus is on the person rather than the thing. Things in themselves have a certain affective value (e.g. they attract, repel or are neutral). This is what motivates the will and directs human intentionality. Ricoeur (1986:151, n.2) puts it thus: 'Now, the movement of the self, in its prereflective naïveté, lies in the intentional moment through which I break through to the world of possibilities, of eventualities, of novel events.' The will assumes objects (people and things) extraneous to me in the same way that I perceive objects as extraneous to me. The affective value of things outside the person arouses

39.Although rationality functions via emotion, we are not always aware of it, because as a rule the emotion is 'neutral'. We could speak of hierarchic rational levels, at which emotion plays a greater or lesser role on the principle that the more it concerns our life world, the more likely that affect will feature. We do not look for an affective dimension in 'neutral' scientific activities such as solving a maths problem, working out a formula, or checking the construction of a bridge. Yet these activities, too, are accompanied by constant interaction between human subject activities, too, are accorined object (cf. Hegel). Affect features more noticeably and rationally detere noticeably in the human with human relations and most conspic personal circumstances.

40.It is remarkable that our sense of touch, which is not unassociated with feeling and emotion, has been neglected ever since the time of the Greeks, Christianity and post-Enlightenment philosophy (see Walton 2004:146ff). The sense of sight (vision) is preferred, because it is associated with light, reason and understanding. Sight was symbolised by fire (the sun) and God lived in inaccessible light. Light, like reason, was conceived of as masculine. Plotinus's One in the Enneads was disembodied, hence not associated with touch. It was symbolised by the sun Touch was symbolised by earth. It also epitomises emotion, desire and is feminine capricious. Separation, which includes infinitude and desire, precludes touch and hence intimacy as well. Yet knowledge without touch is not conceivable. My first impulse on seeing something beautiful or new is to pick it up or touch it. What the impulse on seeing something beautiful or new is to pick it up or touch it. What the eye sees and the hand touches is a single movement. Ward (2007:117-118) puts it thus: Through touch there is movement within the soul such that the whole person person's desire for the othions of desire - the desire of the other as well as that person's desire for the other ...If, then, such intuition, contemplation, imagination movement and desire depend upon touch, then the ensouled flesh in not monadic. It only realizes itself in community; in political and erotic communities or ekklesia.' desire or revulsion and activates the will. This affirms human finitude in the same way perception does. 'Accordingly, if desire is a form of receptivity, analogous to that of perception but different in a way, in what does its infinitude consist?' (Ricoeur 1986:151, n.2).

\section{His answer read as follows:}

It is an experience of lack of ... an impulse toward ... In desire I am outside myself; I am with the desirable in the world. In short, in desire I am open to all the affective tones of things that attract of repel me.

(Ricoeur 1986:52-53)

Ricoeur does not look into the reason why something attracts or repels me, why I desire it or not, why it activates or does not activate my will. ${ }^{41}$ It is probably the result of several complex factors ranging from a particular need that we have at a given time to certain likes and dislikes that develop over a long period. The latter are preferences or tastes acquired over time, which Ricoeur (1986:57ff) calls habit, inertia or a form of perseverance. 'Each of us has his way of loving and hating, and this love and hate reflect his whole personality' (Ricoeur 1986:60). Thus affect determines what emerges in our likes and dislikes, and hence our personality and character. Accordingly, character is not 'not the result of taking a position' (Ricoeur 1986:62) but something I receive and 'I do not know the meaning of this gift that makes me the heir to my own life' (Ricoeur 1986:63).

The synthesis of desire and reason (power of obligation that comes from practical reason) is respect (Ricoeur 1986:73). Reason is practical only if it influences desire:

The important thing is that through this emotion of subdued desire that faculty of desiring is 'elevated' to the level of reason, and that in this way self-esteem is born in the heart of this finitude elevated to reason.

(Ricoeur 1986:74)

\section{Self-transcendence in the mode of a secularised consumer culture}

Emerson's work is the paradigm for secular spirituality that has emerged in recent years. Secular spirituality has the same emphasis on nature, emotion, the unconscious, freedom, unity and self-construction that we find in Emerson. Does that mean we successfully accommodate affectivity in selfknowledge and self-construction? It is a tricky question. In one instance, there is greater emphasis on experience (proliferation of charismatic emotive religions), as well as numerous examples in the field of secular spirituality, with its renewed focus on nature, self, transcendence and the way we can encounter it in meditation and mystical experience.

The entertainment industry focuses on experience and the emotion it evokes. The media zoom in on the drama of catastrophes wherever they happen on our planet. We are moved and respond positively. But the media also present a culture of violence and reified sexuality. On the one

41. Here one is reminded of Girard's philosophy of desire, in which desire is aroused by what the other possesses (see Hegel 1959:123. For Girard's view of desire, see Du Toit 2008:1-33.) 
hand there is greater recognition of our bodily nature as a means to pleasure. On the other hand our individualised society is marked by a loss of fellowship and collective emotion, with the possible exception of sporting events. The plethora of courses in self-discovery, self-construction, selfassertion, self-actualisation and the like certainly promote acknowledgment and a positive image of affectivity.

Transcendent experience and self-transcendence are bound to be different in a disenchanted world. Accounts of natural events cannot but affect our concept of God. Western ontology, which grew from philosophical and theological interpretations, was overthrown by science. Science was put at the service of humankind by technology and available technologies became the main factor in the design of new technologies of self that manifest themselves in present-day consumer society. Transcendence comes via both virtual and real experiences that make up our technological rollercoaster society.

One could argue that transcendence in present-day consumer society differs from all earlier transcendental movements outwards (nature), upwards (God) and inwards (thought, metaphysics). Self-transcendence is characterised not by 'movement towards...' but by 'movement with...' We move in, through and with technology, which has become an extension of self. It is not so much that self-transcendence is effected by the unconscious, by affectivity or by inner creativity. It rather concerns the way in which self-identity is governed by the technologically extended self f $^{42}$ (selftranscendence is increasingly co-determined by social and technological patterns laid down by the consumer, advertising and IT society in which we live). Morality and dialogue with others and self play a dwindling role in selfconstruction (Hankiss 2006:287).

\section{Conclusion}

Self-transcendence is the mode in which we experience ourselves. It is characterised by awareness of desire (Eros) in the form of unfulfilment and incompleteness. Religiously it translates into sin, but it may also be regarded as a natural, inevitable manifestation of consciousness and self-consciousness. Whereas it was once ascribed to transcendent forces acting on human beings, nowadays people are increasingly harnessing it in their attempts at selfconstruction.

Self-transcendence cannot be explained in isolation; human biology, affectivity and the unconscious come into the picture as well. One also has to take into account the contents of consciousness and their influence on people (concepts like separation, infinitude, desire, the O/other). In addition, cultural artefacts also help us to construct

42. Hankiss (2006) mentions everyday things without which self is inconceivable: the first cigarette and coffee in the morning (26ff), mirrors, toothpaste, the gym, coiffure, perfume, makeup, jewellery and shoes (28-43). There are also techniques: coiffure, perfume, makeup, jewellery and shoes (28-43). There are also techniques:
etiquette (75ff), the role of 'white lies' (78ff), as well as the role of mobile phones and the Internet (84ff). He describes how the workplace (101ff) and the home with its objects (123ff) determine self. These things combine to trigger a renaissance of its objects (123ff) determine self. These things combine to trigger
the proletariat (161ff) and the inescapable demise of self (198ff). diverse selves. In view of all this, it is apparent that human wiring for transcendence cannot be confined to a particular religious tradition or theology. In contrast to modernism, people's relation to the other (God, world, fellow humans, ideas) is no longer regulated exclusively by concepts such as metaphysical truth, hierarchy, tradition and established value systems, but by self-construction (see Bildung) that assumes a pragmatic, eclectic style - a worldview reinforced by a human rights culture that endorses freedom (of religion, expression, association, the press, minorities) and dignity irrespective of race, gender, sexual orientation, culture and the like. ${ }^{43}$

Perceptions of self and self-transcendence are changing radically. But must we appraise these changes moralistically? Every generation finds transcendence within the interpretive horizons permitted by their culture, science and worldview. There are biological constants (neocortex, lymphatic system) and mental constants (desire, infinity, unfulfilment), but they manifest themselves differently in every era. The remarkable feature of our age is that transcendence is no longer encapsulated in metaphysical ideas, but comes to us via our techno-scientific environment that sweeps us along on its evolutionary current. We cannot artificially perpetuate the enchantment of a world we have outgrown. And why should we? The Middle Ages would have seen our present-day world as a dream come true and many people today undeniably find fulfilment in a virtual, consumer and pleasure-centred environment. As disenchanted as it may be, it is certainly not devoid of transcendence.

\section{References}

Barabas, M., 1977, 'Transcending the human', in D.Z. Philips \& T. Tessin (eds.), Religion without transcendence?, pp. 177-232, Macmillan, London.

Buber, M., 1939, Man in revolt, Westminster Press, Philadelphia.

Caputo, J.D. \& Vattimo, G., 2007, After the death of God, Columbia University Press, New York.

Dalferth, I.U., 2007, 'Beyond understanding?', in A. Grøn, I. Damgaard \& S. Overgaard (eds.), Subjectivity and transcendence, pp. 37-54, Siebert Mohr, Tübingen.

Dupré, L., 1976, Transcendent selfhood. The loss and rediscovery of inner life, Seabury Press, New York.

Du Toit, C.W., 2004a, 'Diversity in a multicultural and polyethnic world: Challenges and responses', Verbum et Ecclesia 25(2), 442-459.

Du Toit, C.W., 2004b, 'Technoscience and the integrity of personhood in Africa and in the West: Facing our technoscientific environment, in C.W. du Toit (ed.), The integrity of the human person in an African context: perspectives from science and religion, pp. 1-46 Research Institute for Theology and Religion, Pretoria.

Du Toit, C.W., 2007, Viewed from the shoulders of God. Themes in science and theology, Unisa, Pretoria.

Du Toit, C.W., 2008, 'Is religion grounded in evolution? A critical look at some models', in C.W. du Toit (ed.), The evolutionary roots of religion: Cultivate, mutate or eliminate?, Research Institute for Theology and Religion, Pretoria.

Du Toit, C.W., 2010, 'Perspectives on an ethics of power sharing in Africa', in C.W. du Toit (ed.), Power sharing and African democracy, pp. 45-69, Research Institute for Theology and Religion, Pretoria.

Faulconer, J.E. (ed.), 2003, Transcendence in philosophy and religion, Indiana University Press, Bloomington.

Frandsen, H.V., 2007, 'Transcendence of the appeal - Sovereignty of the subject', in A. Grøn, I. Damgaard \& S. Overgaard (eds.), Subjectivity and transcendence, pp. 115-131, Siebert Mohr, Tübingen.

Gill, J.H., 1989, Mediated transcendence. A postmodern reflection, Mercer University Press, Macon.

Gougeon, L., 2007, Emerson and Eros. The making of a cultural hero, State University of New York Press, Albany.

Hankiss, E., 2006, The toothpaste of immortality. Self-constructing in the consumer age, John Hopkins University Press, Baltimore.

43.'People have to construct themselves in a world that worships rationality and, at the same time, longs for spirituality and mysticism' (Hankiss 2006:267). 
Hegel, G.W.F., 1959 [1817], Encyclopedia of philosophy, transl. G.E. Mueller Philosophical Library, New York.

Hegel, G.W.F., 1985 [1827], Lectures on the philosophy of religion, vol. III, The consummate religion, University of California Press, Berkeley.

Hyland, D.A., 1995, Finitude and transcendence in the Platonic dialogues, State University of New York Press, Albany.

Janz, P.D., 2004, God, the mind's desire. Reference, reason and Christian thinking, Cambridge University Press, Cambridge.

Levinas E., 1979 [1969], Totality and infinity, Nijhof, The Hague.

Malpas, J., 2007, 'Heidegger's topology of being', in S. Crowell \& J. Malpas (eds.), Transcendental Heidegger, pp. 119-134, Stanford University Press, Stanford.

Nancy, J.-L., 2002, Hegel. The restlessness of the negative, University of Minnesota Press, Minneapolis.

Parnas J., 2007, 'Subjectivity in schizophrenia: The minimal self is too small', in A. Grøn, I. Damgaard \& S. Overgaard (eds.), Subjectivity and transcendence, pp. 55-70, Siebert Mohr, Tübingen.
Philips, D.Z. \& Tessin, T. (eds.), 1997, Religion without transcendence?, Macmillan, London.

Ricoeur, P., 1986, Fallible man, Fordham University Press, New York.

Ricoeur, P., 1992, Oneself as another, University of Chicago Press, Chicago.

Ryle, G., 1949, The concept of mind, Penguin, Harmondsworth.

Vattimo, G., 2003, Nihilism and emancipation, Columbia University Press, New York.

Walton, S., 2004, Humanity. An emotional history, Atlantic, London.

Ward, G., 2007, 'The logos, the body and the world: On the phenomenal border' in K. Vanhoozer \& M. Warner (eds.), Transcending boundaries in philosophy and theology, Ashgate, Hampshire.

Wider, K., 1977, The bodily nature of consciousness, Cornell University Press, Ithaca.

Žižek, S., 2003, The puppet and the dwarf, Massachusetts Institute of Technology, Cambridge. 